\title{
Research on the Interaction Between Industrial Structure and Urbanization Development in Qingdao
}

\author{
Xuechen Wang, Yingming Zhu* \\ School of Economics and Management \\ Nanjing University of Science and Technology \\ Jiangsu Industrial Cluster Research Base \\ Nanjing, China \\ 1217807565@qq.com \\ zhuyingming@njust.edu.cn*
}

\begin{abstract}
In recent years, industrial structure and urbanization development have been drawing more and more people's attention. China,as the world's most competitive developing country, after 1978, industrial structure and the process of urbanization go to a road of rapid development. Qingdao,one of the earliest coastal opening cities, is a model city opening to the outside world. The study on industrial structure and urbanization is to find the relationship between them and in order to promote the development of Qingdao's economy, while improving the industrial structure and urbanization will lead to achieve the faster development.

Based on the analysis of the industrial structure and the development of urbanization in Qingdao, this paper uses the knowledge of industrial economics and econometrics to analyze the interaction between them. This article uses data between 2000 and 2015 and sets up a mathematical model to test the relationship between them by using Granger causality test.Finally,we find that the industrial structure of Qingdao is inseparable from the development of urbanization and there is a correlation between them.We also find that the industrial structure of Qingdao will drive the evolution of urbanization, but on the contrary, the effect of urbanization in Qingdao on the industrial structure is not very significant.
\end{abstract}

Keywords-The city of Qingdao; The industrial structure; Urbanization development; Interaction

\section{INTRODUCTION}

\section{A. Background}

Under the current international background, the economic growth of various countries is affected by many factors. With the development of economy and advancement of technology, the fourth industrial revolution has emerged and the industrial structure is once again facing adjustments. At the same time, along with the development of urbanization, the country's economy has been given new vitality.

At present, the development of industrial structure and urbanization receives a lot of attention. As one of the coastal cities in China, Qingdao has a strong economic foundation and frequent foreign economic exchanges. Therefore, Qingdao was chosen as the basis for this topic. The purpose of this paper is to use a mathematical model to find a mutual interaction between these two sides.We want to know the interaction so we use Granger causality test,which is a method to test interaction between two things..

\section{B. Literature Review}

In all the studies, it can be found that there is a long history of industrial structure and urbanization in developed countries. Colin Clark (1940) used the research of William Petty as a basis to collate the labor input-output data of three industries in different countries and obtained the "Petty-Clark Theorem". After World War II, Simon Kuznets (1971) proposed six aspects of modern economic growth. Through analysis of a large number of data, the impact of changes in industrial structure on economic development was summarized.[1]Daniel Bell (1973) carefully analyzed the situation and believed the evolution of the industrial structure was an irreversible historical trend that developed from low level to high level and put forward the idea of post-industrial society.[2] Northam(1979)summarized the "Urbanization Process Curve" through the study of specific examples. It was similar to the shape of the English letter "S" and divided the process of urbanization development into three phases.Lucas (1988) believed that human capital was an important factor in linking urbanization with changes in the industrial structure.Carter(1988) studied the relationship between urbanization and industrial structure changes from the perspective of urban system innovation and he found urban innovation activities would improve industrial structure.Davis and Henderson(2003) examined the relationship between urbanization and industrial structure from the perspective of agglomeration economy and found the development of industrial structure could promote urbanization.Jane Jacobs(2007) proved the role of industrial development would promote the city in his book named Theory of Urban Economy.

Chinese scholars also have researched on it. Fenyu Zeng (2002) concluded in the course of economic development, found the development of urbanization had a promoting effect on the industrial structure and at the same time the adjustment of industrial structure could also promote the progress of urbanization.[3] Chenggu Li, Wensheng Zheng and Xiaofang Wang (2004) believed that the continuous improvement of the level of urbanization and the upgrading of industrial structure were inevitable roads for China's economic development. They were divided into types and the interaction patterns between the 
two types.[4] Tengteng Ma (2012) used an empirical analysis method to analyze the relationship between urbanization development and industrial structure changes in Qingdao and concluded that continuous optimization of the industrial structure would promote the development of urbanization.[5]Zhaocheng Li (2015) used empirical analysis to analyze the relationship between industrial structure changes and urbanization development in Qingdao and proposed countermeasures against the problems.[6]

In summary, it can be seen that although scholars have continued to study the industrial structure and urbanization in recent years, the relationship between them is still relatively small compared to the study of industrial structure and urbanization alone. Therefore, the research of the relationship between them needs to continue to receive more attention.So we need to research and use some methods to test it,our research process as follows.

\section{EXPERIMENTAL}

\section{A. Selection of Variables and Description of Data}

Before analyzing the interaction between industrial structure and urbanization in Qingdao, we must first select the appropriate variables.Urbanization is mainly measured by the urbanization rate. Therefore, we use the urbanization rate (M) to analyze the level of urbanization in Qingdao.As far as the industrial structure is concerned, we analyze the industrial structure of Qingdao by using the proportion of industries in three main industries and the proportion of employment. However, in the econometric model, if a large number of variables are introduced, the number of parameters to be estimated will also increase, so that the degree of freedom of the model will be affected and will be reduced. A low level of model freedom will result in a larger analysis result. [7]Because of this impact, the choice of the number of variables should be appropriate. Here, first we analyze the data for 16 years between 2000 and 2015 to reduce the number of variables. For the correlation analysis between variables, the size of the correlation coefficient is mainly observed, and the correlation coefficient is an index that weighs the linear correlation between the variables.

Use the software named Eviews to get the correlation coefficient as follows:

TABLE I. CORRELATION COEFFICIENT BETWEEN URBANIZATION RATE AND THE OUTPUT VALUE OF THREE MAIN INDUSTRIES

\begin{tabular}{|l|l|l|l|}
\hline & \multicolumn{1}{|c|}{$\begin{array}{c}\text { Primary } \\
\text { industry }\end{array}$} & $\begin{array}{c}\text { Secondary } \\
\text { industry }\end{array}$ & $\begin{array}{c}\text { Tertiary } \\
\text { industry }\end{array}$ \\
\hline $\begin{array}{l}\text { Urbanization } \\
\text { rate }\end{array}$ & -0.9779 & -0.5269 & 0.8743 \\
\hline
\end{tabular}

TABLE II. CORRELATION COEFFICIENT BETWEEN URBANIZATION RATE AND THE PROPORTION OF EMPLOYMENT IN THREE MAIN INDUSTRIES

\begin{tabular}{|l|l|l|l|}
\hline & \multicolumn{1}{|c|}{$\begin{array}{c}\text { Primary } \\
\text { industry }\end{array}$} & $\begin{array}{c}\text { Secondary } \\
\text { industry }\end{array}$ & $\begin{array}{c}\text { Tertiary } \\
\text { industry }\end{array}$ \\
\hline $\begin{array}{l}\text { Urbanization } \\
\text { rate }\end{array}$ & -0.9575 & 0.6765 & 0.9711 \\
\hline
\end{tabular}

${ }^{\text {a. }}$ Data sources:Authors sort out the data of Qingdao statistical yearbook
According to Table I, it can be seen the urbanization rate of Qingdao is highly negatively correlated with the primary industry, indicating the continuous decrease in the proportion of the primary industry will increase the urbanization rate rapidly, and the secondary industry shows a low correlation. It shows that the role of the development of secondary industry in urbanization is not very obvious. The tertiary industry shows a high positive correlation. Although the relevance of the secondary industry is not high, the contribution of secondary industry is still very large, so choose the secondary and tertiary industry's output value data for this research.Similarly, according to Table II, it is the same results as Table I,so the employment proportion data of secondary and tertiary industries are selected for this research. The proportion of output value of the secondary and tertiary industries is denoted by $\mathrm{N}_{1}$ and $\mathrm{N}_{2}$, and the proportion of employment is denoted by $\mathrm{W}_{1}$ and $\mathrm{W}_{2}$ respectively. These four variables are used as indicators of the changes in the industrial structure of Qingdao as a whole. In the following, the ratio of urbanization to the proportion of output value and the proportion of employment are examined.

\section{B. Model Specifications}

The correlation coefficient shows that there is a link between the industrial structure of Qingdao and the development of urbanization. However, if we have to look for specific interactions between them, we must use the Granger causality test. Granger causality test was initiated by Clive W. J. Granger, who was the winner of the 2003 Nobel Prize in Economics. This method is used to analyze statistical causality between economic variables,but since its statistics is essentially a kind of prediction of stationary time series data, it is only applicable to econometric variable prediction and cannot be used as a criterion to test true causality. During the entire inspection process, due to the reasons for data collection, we only select the data from 2000 to 2015 for analysis. This will more or less have a detrimental effect on the meaning of the test results and analysis.

Granger causality test is conditional, that is, the linear combination of non-stationary time series should have cointegration, and the co-integration relationship test is the test of the time series variable that has unit root characteristics. Therefore, the inspection process generally includes three aspects: unit root test, co-integration test, and finally the causality test.

So we first establish the mathematical model as follows:

$$
\mathrm{M}_{\mathrm{t}}=\alpha_{0}+\alpha_{1} \mathrm{~N}_{1 \mathrm{t}}+\alpha_{2} \mathrm{~N}_{2 \mathrm{t}}+\mu_{\mathrm{t}}
$$

$$
\mathrm{M}_{\mathrm{t}}=\beta_{0}+\beta_{1} \mathrm{~W}_{1 \mathrm{t}}+\beta_{2} \mathrm{~W}_{2 \mathrm{t}}+\varepsilon_{\mathrm{t}}
$$

In (1) and (2), $\alpha_{0}$ and $\beta_{0}$ are constant terms, and $\alpha_{1}, \alpha_{2}$ denote the impact of the increase in the proportion of the output value of the secondary and tertiary industries on the urbanization rate of Qingdao in (1), $\beta_{1}$ and $\beta_{2}$ denote the impact of the increase in the proportion of employment of the secondary and tertiary 
industries on the urbanization rate of Qingdao in (2), respectively, $\varepsilon_{t}, \mu_{t}$ are the residual sequences.

\section{RESUlTS AND DisCUSSION}

\section{A. Unit Root Test}

The unit root test is performed on the data from the 16 years of Qingdao from 2000 to 2015 to determine whether it is stable. The unit root test results for variables as follows:

From the test results according to Table III, it can be seen that the original sequence is not stable and there are unit roots. After the first-order difference, it is still unstable and there are unit roots. Therefore, when it is second-order difference that all of them are significant at $1 \%$ level, so we could say that they pass the test under the level.Therefore, the original sequence is a second-order single integer sequence.

\section{B. Co-integration Test}

The condition of the co-integration test is that the sequence must be of the same order and the results of the previous test show that the sequence of the five groups is a second-order single integer sequence, so the co-integration test can be performed. This test is used to determine whether the linear regression equation is reasonable. This article adopts the twostep method of E-G to carry out the stability test on the residual sequence items. The test results are shown in Table IV.

From Table IV, it can be seen that the residual sequences pass the test, and it can be seen that there is a co-integration relationship between them, that means there is a long-term stable equilibrium relationship between them.

\section{Granger Causality Test}

When we select lag period is 1 , the test results are shown in Table V. In order to increase the accuracy, the lag period is chosen to be 2 and 3 , and we find that the final results are the same as 1 .

The test results show that the changes in the proportion of output value of the secondary and tertiary industries and the proportion of employment are all Granger causes of changes in the urbanization rate. This indicates that there is a one-way causal relationship between the changes in the industrial structure and the development of urbanization.It means that changes in the industrial structure will promote the improvement of urbanization and drive the development of urbanization.Due to the limitations of the authors' knowledge, the examination of the robustness of the results has not been excessively tested.

\section{CONCLUSIONS}

After the analysis and the test of 16-year's data in Qingdao, we can see that its industrial structure and urbanization are developing very fast. Specifically, in the analysis of the correlation between these two sides, we can know that the industrial structure of Qingdao is inseparable from the development of urbanization and there is a correlation between them. The co-integration test can tell us that there is a longterm equilibrium relationship. Finally, the Granger causality test is used to observe the specific relationship between them, that is, the changes in the industrial structure of Qingdao will drive the evolution of urbanization, but on the contrary, the effect of urbanization in Qingdao on the industrial structure is not very significant.

TABLE III. UNIT ROOT TEST RESULTS OF VARIABLES

\begin{tabular}{|c|c|c|c|c|c|c|}
\hline Variables & ADF test value & Prob. & $1 \%$ critical value & $5 \%$ critical value & $10 \%$ critical value & Results \\
\hline M & -2.3395 & 0.3911 & -4.7284 & -3.7597 & -3.3250 & unstable \\
\hline $\mathrm{N}_{1}$ & -1.9188 & 0.5957 & -4.7284 & -3.7597 & -3.3250 & unstable \\
\hline $\mathrm{N}_{2}$ & -2.0209 & 0.5442 & -4.7284 & -3.7597 & -3.3250 & unstable \\
\hline $\mathrm{W}_{1}$ & -0.8333 & 0.9376 & -4.7284 & -3.7597 & -3.3250 & unstable \\
\hline $\mathrm{W}_{2}$ & -2.5455 & 0.3053 & -4.7284 & -3.7597 & -3.3250 & unstable \\
\hline $\mathrm{M}(1)$ & -2.7893 & 0.2230 & -4.8001 & -3.7912 & -3.3423 & unstable \\
\hline $\mathrm{N}_{1}(1)$ & -2.6423 & 0.2192 & -4.8001 & -3.7912 & -3.3423 & unstable \\
\hline $\mathrm{N}_{2}(1)$ & -3.2927 & 0.1011 & -4.8001 & -3.7912 & -3.3423 & unstable \\
\hline $\mathrm{W}_{1}(1)$ & -2.8430 & 0.2074 & -4.8001 & -3.7912 & -3.3423 & unstable \\
\hline $\mathrm{W}_{2}(1)$ & -2.3665 & 0.3777 & -4.8001 & -3.7912 & -3.3423 & unstable \\
\hline $\mathrm{M}(2)$ & -5.9299 & 0.0000 & -2.7550 & -1.9710 & -1.6037 & stable \\
\hline $\mathrm{N}_{1}(2)$ & -5.4602 & 0.0001 & -2.7550 & -1.9710 & -1.6037 & stable \\
\hline $\mathrm{N}_{2}(2)$ & $\begin{array}{l}-5.7355 \\
\end{array}$ & 0.0000 & -2.7550 & -1.9710 & -1.6037 & stable \\
\hline $\mathrm{W}_{1}(2)$ & -4.2436 & 0.0004 & -2.7550 & -1.9710 & -1.6037 & stable \\
\hline $\mathrm{W}_{2}(2)$ & -4.5133 & 0.0003 & -2.7550 & -1.9710 & -1.6037 & stable \\
\hline
\end{tabular}

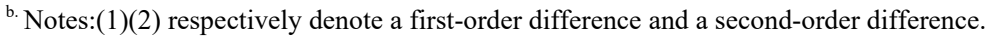


TABLE IV. ADF TEST RESULTS OF RESIDUAL SEQUENCE

\begin{tabular}{|c|c|c|c|c|c|c|}
\hline Variables & ADF test value & Prob. & $1 \%$ level & $5 \%$ level & $10 \%$ level & Results \\
\hline$\mu_{\text {错误!:未找到引用源。 }}$ 。 & -5.0962 & 0.0001 & -2.7406 & -1.9684 & -1.6044 & stable \\
\hline$\varepsilon_{\mathrm{t}}$ & -3.0313 & 0.0051 & -2.7283 & -1.9663 & -1.6050 & stable \\
\hline
\end{tabular}

TABLE V. GRANGER CAUSALITY TEST RESULTS

\begin{tabular}{|l|l|l|}
\hline \multicolumn{1}{|c|}{ Null hypothesis } & F Statistics & Prob. \\
\hline $\begin{array}{l}\text { The change in the proportion of output value of the secondary industry is not a Granger cause } \\
\text { of the change in the urbanization rate }\end{array}$ & 13.5939 & 0.0031 \\
\hline $\begin{array}{l}\text { The change in urbanization rate is not a Granger cause of the change in the proportion of the } \\
\text { output value of the secondary industry }\end{array}$ & 0.5756 & 0.4627 \\
\hline $\begin{array}{l}\text { The change in the proportion of the output value of the tertiary industry is not the Granger } \\
\text { cause of the change in the urbanization rate }\end{array}$ & 3.4131 & 0.0895 \\
\hline $\begin{array}{l}\text { The change in urbanization rate is not a Granger cause of the change in the proportion of the } \\
\text { output value of the tertiary industry }\end{array}$ & 0.5943 & 0.4557 \\
\hline $\begin{array}{l}\text { The change in the proportion of employment in the secondary industry is not a Granger cause } \\
\text { of the change in the urbanization rate }\end{array}$ & 4.8916 & 0.0471 \\
\hline $\begin{array}{l}\text { The change of urbanization rate is not the Granger cause of the change in the proportion of } \\
\text { employment in the secondary industry }\end{array}$ & 0.6392 & 0.4162 \\
\hline $\begin{array}{l}\text { The change in the proportion of employment in the tertiary industry is not the Granger cause } \\
\text { of the change in the urbanization rate }\end{array}$ & 16.8100 & Accepted \\
\hline $\begin{array}{l}\text { The change of urbanization rate is not a Granger cause of the change in the proportion of } \\
\text { tertiary industry employment }\end{array}$ & 0.5769 & 0.0015 \\
\hline
\end{tabular}

\section{ACKNOWLEDGMENT}

We greatly thank the support by the Major Program of National Social Science Foundation of China [15ZDA053], the Key Program of the National Social Science Foundation Project of China [14AZD021], Cultural Experts and "Four batch" Talents Independently Selected Topic Project [ZXGZ[2018]86], the Jiangsu Provice Natural Science Foundation of China [BK20171422], and the Fundamental Research Funds for the Central Universities [30918014110].

\section{REFERENCES}

[1] S. Kuznets, Economic Growth of Nations, America: Harvard University Press, 1971
[2] D. Bell, The coming of post-industrial society, America:Basic Books, 1973.

[3] F.Y. Zeng, "Urbanization and Optimization of Industrial Structure," Contemporary economic research, vol. 9, pp. 31-36, 2002.

[4] C.G. Li, W.S. Zheng, and X.F. Wang, "Study on the Interactive Change Trend of Urbanization and Industrial Structure Evolution in China," Human Geography, vol. 4, pp. 50-54, 2004.

[5] T.T. Ma, Research on the Interaction between Urbanization and Industrial Structure in Qingdao City, Shandong Province,Liaoning: Liaoning University, 2012.

[6] Z.C. Li, Research on the Coupling of Industrial Structure and Urbanization Process in Qingdao, Qingdao: Qingdao University, 2015.

[7] J. Wei and M. Li, "An Empirical Analysis of the Evolution of Industrial Structure and Urbanization: A Case Study of Jiangsu Province," Forum on Science and Technology in China, vol. 11, pp. 83-87, 2009. 